\title{
Blending the Gender Lines: Effectiveness of Beauty Boys as Brand Endorsers
}

\author{
Sarah E Frankel* \\ University of Tennessee, USA
}

*Corresponding author: Sarah E Frankel, Department of Retail, Hospitality, and Tourism Management, University of Tennessee, Knoxville, USA.

Received Date: December 19, 2019

Published Date: January 09, 2020

\section{Introduction}

In 2016, the cosmetic market grew an estimated of four percent globally in comparison to the previous year; revenue for this segment amounts to approximately $\$ 13.6$ billion and is expected grow annual by $3.7 \%$ in 2018 [1]. With the healthy growth of the cosmetic market there are signs that highlight inclusive practices that can be attributed to this growth. Boy beauty and gender-neutral make-up have contributed to this development with offering malefocused beauty products [2]. More companies like ASOS, Calvin Klein, Yves Saint Laurent, and Clinique offer makeup for men while disruptive startup companies like Context and incumbent brands such as MAC, Tom Ford, and Marc Jacobs have propelled inclusive gender-neutral make-up campaigns [2]. This has even sparked mega-beauty brands such as Maybelline and Covergirl to announce male brand ambassadors. These ambassadors, known as beauty boys, are male make-up artists who have gained recognition as internet celebrities by utilizing social media platforms. The impact of influencers online, such as beauty boys, can be strategically used as an effective marketing tool, has aroused both marketers' and investors' interest [3].

Perhaps unsurprisingly, little research has attempted to address male beauty brand ambassadors for influencer marketing. So far research has focused on celebrity endorsement and well documented its positive effects. Positive effects of influencer endorsement are well documented in extant literature; celebrity endorsers have been identified as a favorable way to generate attitudinal and behavioral responses among consumers [3-7]. Research on celebrity endorser effectiveness has centered around endorser characteristics such as a consumer's perception of a celebrity's personality characteristics with the consumer's selfconcept or a match between a product and the endorser [3]. There is sufficient evidence for the notion that consumers purchase and consume products congruent with their actual or ideal selfconcept [5], yet prior research has overlooked the emerging facet of endorsement in beauty that is gender incongruent and could be consider deviant to the targeted consumer demographic.

The beauty market is a volatile, innovative and boundary pushing facet of the fashion industry and can be a valuable site for revisiting established theory. Thus, the purpose of this article is to act as a catalyst for developing an understanding on how congruency effects consumer behavior when accounting for inclusive images in advertisements. Specifically, examining the impact of congruency between beauty boy ambassadors' endorsement and female consumers on their behavior intention; and also, determining possible factors that influence the beauty boy ambassadors' endorsement effectiveness in terms of fashion advertisements.

\section{Proposed Market Segment}

Generation Y, Millennials, and Gen Z demonstrate an inclination to embrace celebrities as brand endorsers and their behavioral intentions are affected by their veneration of the influencer [7,3]. More specifically, millennials continue to demonstrate a desire for inclusive advertising that radiates authenticity [8,7]. This type of advertising can include images of individuals from minorities, individuals whom have disabilities, or models that go against the hegemonic depiction of the mainstream consumer segment. This acceptance of inclusive advertising is also attributed to the paradigm shift in the make-up industry that is blending the lines of traditional gender roles [4]. I propose that there should also be a focus on the GenZ consumer and their perceptions of this new marketing technique. Gen Z, individuals born after 1998, have 
become an appealing demographic for marketers. They account for a fourth of the population in North America and are also the most ethnically diverse generation ever with influence of over $\$ 600$ billion in family spending [9].

\section{Why Beauty Boys?}

Many beauty boys acknowledge the influence that drag makeup has had on their aesthetic, though they are not performing as women, rather they are wearing make-up as men [10]. The fact that young men do not necessarily equate make-up and femininity indicates a new chapter in the beauty industry: a modern development to what drag culture pioneered for most of the 20th century [10]. The adoption of male beauty models continues to expand in the fashion beauty market due to large brands, social media, and television.

CoverGirl is currently the third-largest color cosmetics brand in the U.S., following L'Oreal's Maybelline and Estee Lauder's MAC [9]. This beauty giant has led a revolution in marketing in a notable way. They have become increasingly aware of the rise of diversity in the millennial consumer group, noting the appreciation for authenticity and trustworthiness in brands $[9,11]$. While this has been important to millennials, marketing ads have become more inclusive in terms of showing more diversity and less restrictive gender roles [9]. Male vloggers are popular on YouTube, Instagram and other social channels. Along with the rise of the long running reality TV show, RuPaul's Drag Race, has highlighted a broader acceptance of beauty products beyond the core cisgender female audience [9]. In response to shifting demographics and a desire for inclusive marketing, Covergirl made an announcement that created the first wave a paradigm shifts in the mainstream beauty industry. On October 11, 2016, CoverGirl announced that that 17-year-old Instagram beauty guru, James Charles would be the newest face of the brand, making him the first male CoverGirl spokesperson [12]. So Lashy by blastPRO Mascara was the first advertisement to include a male spokesperson for the brand, which soon led to TV commercials including James Charles [12].

It should be noted that male beauty gurus and endorses have been around prior the James Charles endorsement, companies like Milk Makeup and Anastasia Beverly Hills have been featuring men in advertising campaigns and on displayed images on social media for a more universal and inclusive approach to beauty [13]. But due to CoverGirl's mainstream adoption of male endorsers, it created a shift that led other major beauty competitor, Maybelline to respond by bringing on a boy beauty guru in January 2017; Maybelline announced they would be bringing Manny Gutierrez, the online boy beauty sensation Manny MUA, to be the face of the Big Shot Mascara by Colossal campaign [13].

These are just two mainstream examples of the beauty boys blending lines between male and female beauty. The diversity of these endorsers transcends gender and race and demand further examination. These brands are setting a revolution in mainstream beauty that is disrupting traditional marketing strategies.

\section{Self-Concept and Congruency}

Self-concept has been identified as a multi-dimensional concept reflecting various aspects of self-perspective (e.g., actual self-congruency, ideal self-congruency, social self-congruency, ideal social self-congruency) [14-16]. Within the multi- dimensional framework, the actual self-concept refers to how a person actually perceives himself or herself, whereas the ideal self- concept refers to how a person would like to perceive himself or herself; social self-concept refers to how an individual thinks other perceive him or her, whereas ideal social self-concept represents the way the individual desires to be perceived by others $[14,16]$. Self-congruity theory proposes that consumer behavior is partially determined by a cognitive match-up between value-expressive attributes of a product or brand and consumer self-concept $[12,18]$. Selfcongruity can be considered an extension of self-concept [16]. The foundations of self-congruity theory are rooted in a consumer desire to select products or brands that correspond to one's selfconcept [16].

Moreover, while Sirgy MJ [14] identified four types of selfcongruity, researchers argue that actual self-congruity and ideal self-congruity have the strongest empirical support [16,3]. This match between a product and an individual's actual self-image has been referred to as self-congruity. In contrast, a match between a product and an individual's ideal self-image has been referred to as ideal congruity. Therefore, this study will only focus on these two aspects of self-congruency (actual and ideal self-congruency). This will be contextualized within this study as female consumers exposed to makeup endorsers of two genders; male and female. The stimuli will cause disruption to actual-self congruency because the female sample should not identify with the gender of the male endorser; the ideal self-congruency will be aligned with the female sample wanting to achieve the aesthetic of the beauty boy whose skill with makeup has led to his fame and ultimately the endorsement job.

Research has found that high when self-congruity/high ideal self-congruity conditions are met, the consumer is motivated to purchase an endorsed product; this consumption satisfy both the consumer's self-esteem and self-consistency needs $[8,15]$. The goal of an endorser is to activate purchase motivations in consumers. In a high self-congruity/low ideal self-congruity condition, the consumer might experience a conflict regarding the product, because consumption of it would frustrate the self-esteem need and in another satisfy the self-consistency need [15]. This produces a conflict purchase motivation but can ultimate lead to purchases intention through congruency activation. Under a low self-congruity/high ideal self-congruity condition, the situation is reversed but the motivational outcome remains the same as self-congruity/low ideal self-congruity condition. The consumer would also experience a conflict between the self-esteem and selfconsistency motives because the consumption of the product would satisfy the self-esteem need but would also frustrate their selfconsistency need [15]. Specifically, produces a conflict purchase 
motivation but due to ideal-congruency the activation of selfconsistency motivates approach behavior. The final interrelation is a low self-congruity/low ideal self-congruity condition, the consumer is motivated to avoid the product, since its consumption would frustrate their self-esteem and self-consistency needs $[17,15]$. This produces the worst-case scenario for an endorser by activating avoidance motivations resulting in avoidance purchase motivations.

Advertisers generally accept that the effectiveness of celebrity endorsements due to a perceived increase in credibility and being more attractive and thus enhancing the match of unique qualities of an endorser with that of a product $[6,7]$. Examining the congruency between the brand endorser and the product along with the congruency between the brand endorser and the consumer is pivotal for the endorsement process [5,6]. Researchers have also found that purchasing and using the celebrity-endorsed product assists consumers in obtaining meanings and values that contribute to constructing their self-concept (Xu \& Pratt, 2018). This process of meaning transfer occurs with the formation of celebrity image, followed by shift of meaning from celebrity to the product, and in turn to the consumer [6]. Therefore, the symbolic meaning of the celebrity should be congruent with the product that is being advertise (e.g., match up).

The perception of a credible endorser has such intrinsic attributes as trustworthiness, expertise, and attractiveness [6,11]. Social media influencers display high level of integrity and honesty within their communications with consumers which establish a positive reputation for their potential endorsement engagements [18]. By adopting beauty boys, who have built their brand from social media, the intrinsic credentials of the endorser can be met. These individuals have created an authentic brand that radiate authenticity and expertise that has been demonstrated on social media platforms. This provides a new interpretation of consumers' perception of trust, expertise physical attractiveness into the dialog.

Consumers are motivated to establish their ideal self and may see certain influencers as inspirational figures [3]. Beauty boys have established themselves within social media based on their ability to use makeup and beauty products and this might influence consumers' ideal self-congruency to be activated. Therefore, consumers are likely to imitate their behaviors and adopt the products and attitudes endorsed by the influencer whose images are congruent with consumers' ideal self-image.

While celebrity endorsers and congruency has been explored $[3,5,7]$, looking at social media influencers within beauty branding and marketing has yet to be deeply investigated. Specifically, since the beauty boys that this article identifies on are internet celebrities and might not be familiar to all consumers, this phenomenon warrants further exploration. Though research has determined that when the millennial consumer views an image of the unfamiliar celebrity and the image of the product as congruent the attitudes toward the advertisement and brand were positive [7]. These findings demonstrate that an unfamiliar celebrity endorser and the brand can lead to an effective endorsement; in turn the advertisement is perceived as more believable to millennial consumers.

\section{Future Research}

With the rise of inclusive images and the continued innovation in blending gender lines in beauty, I hope to lay a foundation for the need to future examine the use of beauty boys to market to different consumer segments. This can be done in numerous ways with exciting methodologies and traditional theoretical perspectives.

\section{Acknowledgement}

None.

\section{Conflict of Interest}

No conflict of interest.

\section{References}

1. Statista (2017) Cosmetic Industry- Statistics \& Facts.

2. CBInsights (2018) 13 Trends Shaping the Face of Beauty in 2018.

3. Xu X, Pratt S (2018) Social media influencers as endorsers to promote travel destinations: An application of self-congruence theory to the Chinese Generation Y. Journal of Travel \& Tourism Marketing 35(7): 958-972.

4. Amos C, Holmes G, Sutton D (2008) Exploring the relationship between celebrity endorser effects and advertising effectiveness: A quantitative synthesis of effect size. International Journal of Advertising 27(2): 209234.

5. Choi SM, Rifon NJ (2012) It is a match: The impact of congruence between celebrity image and consumer ideal self on endorsement effectiveness. Psychology \& Marketing 29(9): 639-650.

6. Kamins MA, Gupta K (1994) Congruence between spokesperson and product type: A matchup hypothesis perspective. Psychology \& Marketing 11(6): 569-586.

7. McCormick K (2016) Celebrity endorsements: Influence of a productendorser match on Millennials attitudes and purchase intentions. Journal of Retailing and Consumer Services 32: 39-45.

8. Frankel SE, Ha S (2018) Something seems fishy: Mainstream response to drag queen imagery.

9. Kell J (2016) CoverGirl's First-Ever Male Model is Genius Gen Z Marketing.

10. Beck K, Valenti L (2016) The Beauty Boys of Instagram.

11. Silvera DH, Austad B (2004) Factors predicting the effectiveness of celebrity endorsement advertisements. European Journal of Marketing 38(11/12): 1509-1526.

12. Abelmen D (2016) Meet the First Male CoverGirl, James Charles.

13. Riemel E (2017) Manny Gutierrez Is the First Man to Star in a Maybelline Campaign, and It's a Huge Deal.

14. Sirgy MJ (1982) Self-concept in consumer behavior: A critical review. Journal of Consumer Research 9(3): 287-300.

15. Sirgy MJ (1985) Using self-congruity and ideal congruity to predict purchase motivation. Journal of Business Research 13(3): 195-206.

16. Usakli A, Baloglu S (2011) Brand personality of tourist destinations: An application of self-congruity theory. Tourism Management 32(1): 114127.

17. Kressmann F, Sirgy MJ, Herrmann A, Huber F, Huber S, et al. (2006) Direct and indirect effects of self-image congruence on brand loyalty. Journal of Business Research 59(9): 955-964.

18. Scott M (2018) An analysis of how social media influencers utilize trust-building strategies to create advocates. Journal of Promotional Communications 6(2): 260-273. 